\title{
Further comments concerning preference for signaled shock conditions
}

\author{
PIETRO BADIA \\ Bowling Green State University, Bowling Green, Ohio 43403 \\ and \\ JOHN HARSH \\ State University of New York, Genesco, New York 14454
}

\begin{abstract}
Several reports by Furedy and Biederman are reviewed and inaccuracies in these reports are identified. Their conclusions regarding the findings of others are challenged. In addition, possible reasons for Furedy and Biederman's difficulties in replicating the findings of others are described.
\end{abstract}

It has been noted that critical comments dealing with empirical and theoretical issues are essential for the development of a discipline. In this regard, the comments of Biederman and Furedy $(1973,1976)$ and Furedy and Biederman (1976, Note 1) have been constructive and have provided the reader with alternative accounts of findings dealing with preference for signaled shock conditions. However, in the process of presenting their views, they have inaccurately reported some of the literature. If their reports are left unchallenged, they may mislead the reader. In the first section below, we deal with this problem. The second section identifies some factors that may be responsible for Furedy and Biederman's failure to replicate the findings of others.

A common theme in their reports is that preference for signaled shock is a function of modifiability. They claim that signaled shock situations are of higher value than unsignaled ones when shocks are modifiable but not when shocks are unmodifiable (Biederman \& Furedy, 1970, 1973, 1976; Furedy \& Biederman, 1972, 1976). Biederman and Furedy (1973) state that their findings are similar to those of other investigators who used unscrambled shock. They say "It bears emphasis that the PSS [preference for signaled shock] phenomenon in the TU group, although statistically significant was not marked. However, the value of $60.8 \%$ approximates the size of the PSS found by other investigators who used unscrambled grids (e.g., Perkins et al., 1966)." Their statement misleads the reader by implying that preference for the signaled shock condition is typically weak. This is not so. For example, Perkins, Seymann, Levis, and Spencer (1966), when using a 5-sec shock similar to that used by Biederman \& Furedy, found that

This report was supported in part by Grant GB-33725 from the National Science Foundation and funds from the Faculty Research Committee of Bowling Green State University. Requests for reprints should be addressed to Pietro Badia, Department of Psychology, Bowling Green State University, Bowling Green, Ohio 43403. subjects chose the signaled side about $80 \%$ of the time. In addition, the third experiment of the Perkins et al. study showed that three of four groups also preferred the signaled side better than $80 \%$ of the time with an 18 -sec signal and a .5 -sec shock. In brief, the study by Perkins et al. shows that, with certain parameter values, preference for the signaled condition is marked, while with other values it is not. The study by Lockard (1963) is also at variance with the conclusions of Biederman and Furedy. Unscrambled grid shock was used in this study, and subjects preferred the signaled condition about $90 \%$ of the time. The same marked preference did not occur in a later study (Lockard, 1965) when shock and signal parameters were varied. Biederman and Furedy's comment that $60.8 \%$ approximates the size of the preference for signaled unscrambled shock is wrong.

In the same report, Biederman and Furedy (1973) pursue their argument that the signal condition is preferred because it "assists otherwise unauthorized modification of shock." As support for their views, they state, "In addition, as in these other studies (e.g., Perkins et al., 1966), the preference did not show the orderly course of development expected on the basis of simple learning." Biederman and Furedy cannot base this conclusion on the Perkins et al. study since the sessions in the latter study were each $10 \mathrm{~h}$ long and data points were plotted by sessions. Their conclusion would require that the data points represent smaller time periods. Others have done this and their data contradict the Biederman and Furedy statement. Lockard (1963) and Perkins, Levis, and Seymann (1963) found a gradually increasing negatively accelerated learning function for unscrambled shock, as did Arabian and Desiderato (1975), Hymowitz (1973), and Knapp, Kause, and Perkins (1959). In Arabian and Desiderato (1975), training sessions with shock and testing sessions without shock were used. No avoidance was possible during the testing phase since shock was withheld, yet a strong preference for the condition previously associated with 
the signaled shock was found. In the Hymowitz (1973) study, scrambled shock was used and the function was very similar to that obtained by Arabian and Desiderato (1975), Lockard (1963), and Perkins et al. (1963). Contrary to the assertions of Biederman and Furedy, the "orderly course of development expected on the basis of simple learning" has been shown repeatedly for preference for signaled shock from 1959 until the present.

Controversy over replicating the research of others can sometimes be traced to procedural variations between studies. Unfortunately, Biederman and Furedy (1976) have mistaken other investigators' procedures. They state that "The practice of pretraining or preexposure to the signaled and unsignaled conditions has been standard for all shuttlebox experiments since the first reported by Lockard (1963)." This is simply not the case. Lockard (1963), in fact, used pretraining neither in her first nor in her second report (Lockard, 1965), nor did Hymowitz (1973) or Miller, Daniel, and Berk (1974), all of whom also used shuttleboxes.

Biederman and Furedy (1973) and Furedy and Biederman (Note 1) criticize the procedure used by Badia and Culbertson (1972), which is their option, but they incorrectly describe that procedure. They then build a case against Badia and Culbertson based on their mistaken idea of that procedure-the same procedure, incidentally, that they claim to have replicated exactly (Furedy \& Biederman, 1976, Note 1). Among other things, they state, "We shall argue below that the results obtained by Badia and Culbertson can be fully accounted for by photic reinforcement" (Biederman \& Furedy, 1973 , p. 384). They then describe the experiment incorrectly as using only light onset as a correlated stimulus identifying the signaled condition. In fact, the onset of a light served as the correlated stimulus for some subjects, while termination of a light served as the correlated stimulus for others (Badia \& Culbertson, 1972, p. 463).

These authors are severe in their criticism of the changeover procedure used by Badia and his associates (Biederman \& Furedy, 1973, 1976; Furedy \& Biederman, 1974, Note 1). They are, however, inconsistent. For example, Furedy and Biederman (1974, Note 1) devote considerable space to criticizing the changeover procedure but later assert that Safarjan and D'Amato (Note 2) provide evidence for preference for signaled shock. But Safarjan and D'Amato used the changeover procedure!

Biederman and Furedy's description of the Arabian and Desiderato (1975) findings could seriously mislead the reader. Some additional information is needed to grasp fully the extent to which the latter may occur. As noted, a number of investigators have found preference for signaled over unsignaled shock (e.g., Arabian \& Desiderato, 1975; Badia \& Culbertson, 1972; Hymowitz, 1973; Lockard, 1963; Miller et al., 1974; Perkins et al., 1966). Interpretations of these findings have varied. Some interpretations emphasize the role of stimuli predicting shock or shock periods. Other interpretations emphasize the role of a stimulus identifying safety, that is, shock-free periods. Recently, several researchers have found evidence that the stimulus identifying the shockfree period controls preference for signaled shock (Arabian \& Desiderato, 1975; Badia \& Culbertson, 1972; Badia et al., 1976; Harsh \& Badia, 1976). Whether stimuli identifying shock or whether stimuli identifying shock-free periods control choice of the signaled condition remains an issue of theoretical interest. It is, therefore, imperative that this distinction between shock and shock-free periods not be blurred in describing research.

It is against this background that the statements by Biederman and Furedy (1976) concerning the Arabian and Desiderato study should be evaluated. They claim that Arabian and Desiderato found a preference for unsignaled shock. They state, "Indeed, strong support for a PUS [preference for unsignaled shock] outcome in the shuttlebox has recently been published by Arabian and Desiderato (1975)." But Arabian and Desiderato state that "The results of this study generally support the conclusion that signaled shock is preferred to unsignaled shock because in the former condition, the absence of the preshock condition acts like a safety signal." The degree to which Biederman and Furedy may mislead the reader can be seen most clearly when all three groups of the Arabian and Desiderato study are described. Group A was given a choice between a condition in which a safety signal and a preparatory (warning) signal were present and a condition in which neither of these signals was present. This is the standard signaled vs unsignaled shock condition. Subjects spent about $90 \%$ of the time in the signaled condition, a finding not noted by Biederman and Furedy. Group B was given a choice between a safety signal but with no warning signal prior to shock vs neither a safety signal nor warning signal (shock and signal were presented randomly). Both conditions had unsignaled shock but, in one, safety was identified. These subjects also spent about $90 \%$ of the time at asymptote in the signaled condition. Neither is this finding noted by Biederman and Furedy. However, they do mention Group C. For this group, a choice was given between a condition in which both a safety and a warning signal were presented and a condition in which a safety signal was present but the warning signal occurred independently of shock. Subjects in this group chose the condition in which only safety was identified. To conclude, as Biederman and Furedy have, that the data of Arabian and Desiderato (1975) provide strong support for a preference for unsignaled shock rests on the selective use of evidence. Such a conclusion is a distortion of the Arabian and Desiderato findings.

\section{Parameter Values and Replications}

As noted, many researchers in various laboratories have found that subjects prefer signaled to unsignaled shock conditions, whether shock is scrambled, unscrambled, or presented through surface electrodes (Badia \& Harsh, 1977). Why do Furedy and Biederman have difficulty reproducing these findings? The reasons may 
rest with the procedures and the parameter values used.

One difficulty may be that Furedy and Biederman have not stayed with a paradigm sufficiently long to explore its potential. They have pursued the same issue (modifiable vs unmodifiable shock) using a conditioned suppression paradigm (Biederman \& Furedy, 1970; Furedy \& Biederman, 1972), a concurrent schedule (Biederman \& Furedy, 1973), and a shuttlebox (Furedy $\&$ Biederman, 1976). Unfortunately, while varying their paradigm, they have at the same time varied parameter values. Selecting novel parameter values while using a novel procedure is a gamble. And, in this case, since Furedy and Biederman have been unsuccessful in replicating the findings of others, a gamble that they lost.

Another difficulty relates to their selection of specific parameter values. Furedy and Biederman's parameter values are unusual. In most of their studies, a 5-sec shock duration was used, including two which used a conditioned suppression paradigm (Biederman \& Furedy, 1970; Furedy \& Biederman, 1972). Other researchers typically use shorter durations. The use of such long durations may be one reason why Furedy and Biederman have found the method of shock delivery to be important and why their findings differ from those of others. Subjects experiencing long-duration unscrambled shock of $5 \mathrm{sec}$ are more likely to locate grid bars of the same polarity than those receiving short-duration shock of $.5 \mathrm{sec}$. Why Furedy and Biederman do not discuss this possibility is indeed puzzling. The phenomenon they have studied may be very different from that studied by those other investigators whom they are criticizing.

Other parameter values selected by Furedy and Biederman have been unusual. Biederman and Furedy $(1970,1973)$ and Furedy and Biederman (1972), in their investigation of signaled and unsignaled shock conditions, used unusually high densities of shock relative to that used by others. They presented 5-sec shocks on a variable-time (VT) $30-\mathrm{sec}$ or VT 45-sec schedule. It is unusual to use such high shock densities. Indeed, recent evidence suggests that preference for the signaled condition is importantly related to the density value of the shock schedule (Harsh \& Badia, 1976). In this study preference for the signaled condition did not occur with a VT 45-sec schedule. Additional data are needed, however, before firm conclusions can be drawn about shock density. For the present, considerable caution should be used in comparing the outcomes of the Furedy and Biederman studies with outcomes of others.

Finally, two aspects of their findings suggest that the phenomenon that Furedy and Biederman have studied may be different from that studied by others. One aspect relates to pretraining; the other relates to the performance curve depicting preference. Furedy and Biederman (1976) found a preference for the signaled condition with unscrambled shock but not with scrambled shock only when pretraining was not used. This finding is at odds with other studies. Pretraining has not been an important factor with others, and a preference for the signaled condition develops whether or not pretraining is given and whether or not shock is scrambled or unscrambled. The second aspect noted above relates to the development of preference. The preference for the signaled shock condition described by Furedy and Biederman appeared abruptly, giving no indication of strengthening or weakening with continued testing (Biederman \& Furedy, 1970, 1973; Furedy \& Biederman, 1972, 1976). These observations contrast sharply with those of others using unscrambled shock (Arabian \& Desiderato, 1975; Hymowitz, 1973; Lockard, 1963; Perkins et al., 1963), all of which found a gradually increasing curve.

Contrary to the comments of Furedy and Biederman, preference for signaled over unsignaled shock seems firmly established (see Badia \& Harsh, 1977, for a review).

\section{REFERENCE NOTES}

1. Furedy. J. J., \& Biederman, G. B. Methodological problems in pvaluating rut priference for signaled or unsignaled shock. Paper prescnted at the Psychonomic Society Meetings. Boston, Massachusetts, 1974.

2. Salarjan. W. R., \& D'Amato, M. R. Discriminated shockfree periods as the controlling variable in preference for signaled shock. Paper presented at the Eastern Psychological Association Meetings. New York. New York. 1975.

\section{REFERENCES}

Arabian. J. M.. \& Desiderato, O. Preference for signaled shock: A test of two hypotheses. Animal Learning \& Behavior. 1975, 3. 191-195.

Badia. P.. \& Culbertson, S. The relative aversiveness of signaled vs. unsignaled escapable and inescapable shock. Journal of Experimental Analysis of Behavior. 1972, 17. 462-471.

Badia, P.. \& Harsh. J. Preference for signaled over unsignaled shock schedules: A reply to Furedy and Biederman. Bulletin of the Psy'chonomic Society, 1977, 10, 13-16.

Badia, P., Harsh. J., Coker, C. C., \& Abbott. B. Choice and the dependability of stimuli that predict shock and safety. Journal of the Experimental Analysis of Behavior, 1976, 26, 95-111.

Biederman. G. B.. \& FuREDY, J. J. The preference-for-signaledshock phenomenon: Signaling shock is reinforcing only if shock is modifiable. Quarterly Journal of Experimental Psychology. 1970, 22. 681-685.

Biederman. G. B.. \& Furedy, J. J. Preference for signaledshock phenomenon: Effects of shock modifiability and light reinforcement. Journal of Experimental Psychology, 1973, 100, 380-386.

Biederman. G. B.. \& FUREdy, J. J. The preference-for-signaledshock phenomenon: Fifty days with scrambled shock in the shuttlebox. Bulletin of the Psychonomic Society, 1976, 7. 129-132.

Furedy. J. J.. \& Biederman, G. B. Development of the reinforcing effect of signaling modifiable shock. Perceptual and Motor Skills, 1972, 35. 31-34.

Furfedy, J. J.. \& Biederman, G. B. Preference for signaled shock phenomenon: Direct and indirect evidence for modifiability factors in the shuttlebox. Animal Leaming \& Behavior. 1976. 4. 1.5. 
HaRsh, J., a Badia, P. A temporal paranteter influencing choice between signaled and unsignaled shock schedules. Journal of the Experimenlal Anulysis of Behuvior, 1976, 25, 327-333.

Hymowitz, N. Preference for signaled electric shock. Proceedings of the 8lst Annual Convention of the American Psichological Association. 1973, 847-848.

Knapp, R. K., Kause, R. H., \& Perkins, C. C., JR. Immediate vs. delayed shock in $\mathrm{T}$ ma<e performance. Journal of Experimentul Psychology. 1454. 58, 357-362.

I.JCKARD, J. S. Choice of warning signal or no warning signal in an unavoidable shock situation. Journal of Comparative and Phisiological Psichologit. 1903. 56, 526-530.

IockARD, J. S. (hoice of warning signal or none in several unaroidable shock siluallons. Psplichomomic Sitence. 1965. 3. 5.6.
MIILER. R. R., DANIEL, D. \& BERK, A. M. Successive reversals ut a discriminated preference for signaled tailshock. Animal Learing \& Behavior, 1474, 2, 271-274.

Perkins, (. C.. JR., Levis, D. F., \& Seymann, R. Preterence tor signal-shock vs. shock signal. Psychological Repurts, 1963, 13. 375-378.

Prekins, C. C.. JR., Seymann, R. G., Levis, C. J., \& Spencer, H. R.. J $J_{k}$. Factors affecting prefierence for signal-shock over shoch-signal. Journal of Experimental Psycholog. 1\%66, 72. I (x). 140. 